\title{
ASÉP SUNANDAR SUNARYA: \\ MENJADI DALANG WAYANG GOLÉK YANG POPULER
}

\author{
Masyuning \\ Prodi Karawitan Fak. Seni Pertunjukan \\ Institut Seni Budaya Indonesia (ISBI) Bandung \\ Email: masyuning@isbi.ac.id
}

\begin{abstract}
Not many people knew Asép Sunandar's journey who became famous dalang in West Java, Indonesia. The topic of Asép Sunandar led me to research and write this paper. I began formulating the topic as sinden at Asép Sunandar's theater troupe. I know that I was doing ethnomusicology or fieldwork: by getting to know Asép Sunandar who made the new style of wayang golék performances, studying and performing the music itself, and talking to whoever had the patience to listen to me. The conclusion of paperwasAsép Sunandar focused on the innovative nature of the wayang golék performance.
\end{abstract}

Keywords: Dalang, Popular, Wayang

\section{A. Pengantar}

Asép Sunandar Sunarya merupakan salah seorang dalang fenomenal di Jawa Barat. Keberadaannya telah memberikan sumbangsih pada jagat wayang golék di Jawa Barat. Hal itu begitu terasa ketika dalang ini pergi menghadap Sang Khaliq, menyisakan kesedihan dan kehilangan besar, terutama bagi para penggemar fanatiknya. Hingga tulisan ini dibuat, dirasakan belum ada sosok dalang yang dapat menggantikannya. Kalau pun ada, tentunya harus melewati proses seleksi alam yang panjang, di mana yang bersangkutan mesti menunjukkan loyalitas dalam berprofesi, dan 'keunggulan' yang sepadan atau setidaknya mampu mendekati hasil karya yang ditorehkan Asép Sunandar Sunarya semasa hidup.

Bagi masyarakat awam, nama Asép Sunandar Sunarya mungkin tidak asing. Tetapi tidak seluruh masyarakat yang mengetahui perjalanan sang dalang mengawali karier dan perjuangannya menghimpun massa yang menjadi pendukungnya. Ada proses perjalanan yang dialami oleh sang dalang yang 'tersembunyi' dan belum terungkap, karena tertutup kebesaran namanya. Oleh karena itu, tulisan ini mencoba mengupas eksistensi Asép Sunandar Sunarya, terutama perjuangan pada awal kemunculannya, dan konsep yang ia tawarkan sehingga berdampak pada 
pengakuan sebagai dalang yang disebut superstar.

\section{B. Metode}

Metode yang diterapkan penulis untuk mewujudkan artikel mengenai sang dalang dari Jelekong Kabupaten Bandung, Asép Sunandar Sunarya, berdasarkan pengalaman empiris selama menjadi juru sinden pada rombongan Giri Harja III yang dipimpin Asép Sunandar Sunarya. Selain itu tulisan yang disajikan merupakan hasil pengumpulan informasi dari sejumlah literatur, terutama media massa yang mengabadikan 'sepak terjang' sang dalang pada awal kemunculannya. Informasi yang didapat diidentifikasi sebagai konsep yang ditawarkan dan diimplementasikan Asép Sunandar, sehingga ia tampil berbeda dengan dalang lain. Perbedaan tersebut yang menyebabkan Asép Sunandar Sunarya unik dan fresh bagi aktualisasi pertunjukan wayang golék.

\section{Pembahasan}

Pembahasan dimulai ulasan surat kabar yang meliput Asép Sunandar Sunarya, ketika itu masih sebagai dalang muda yang mampu menarik perhatian masyarakat, karena ketidaklaziman (penulis menyebutnya kebaruan) dalam menyajikan garap wayang golék. Surat kabar yang terbit pada tahun 1984 itu, dikutip sebagai berikut:

Edan: Lewat tengah malam, ketika kantuk mulai menyerang ribuan pasang mata penonton wayang golek di daerah Majalaya, tiba-tiba saja mereka terkesiap menyaksikan adegan gilagilaan. Salah satu wayang danawa yang baru saja adu kekuatan dengan Astrajingga, menggelepar-gelepar. Kepalanya berantakan dihantam bandring. ${ }^{1}$

Demikian Surat Kabar Kompas mengulas Asép Sunandar Sunarya saat menyajikan pentas wayang golék di tahun 1984, dengan bentuk sajian yang tidak lazim untuk pertunjukan wayang golék pada masa itu. Boneka wayang yang dikategorikan bukan bentuk pakeman', seperti danawa (raksasa) - oleh Asép Sunandar Sunarya - diolah melalui sentuhan kreatif, agar mewujudkan 'trik' tampilan boneka yang realistis dan mendukung dramatisasi lakon. Hal itu terbukti dengan respon positif penonton yang terkejut menyaksikan pertunjukan wayang yang relatif seperti 'sungguhan', di mana kepala wayang bisa terbelah berantakan, atau wayang yang muntah mie, dan mulut wayang yang menghisap dan mengeluarkan asap rokok. Kreativitas Asép Sunandar pada masa itu, mengindikasikan bahwa di kemudian hari, ia menjelma menjadi dalang yang sukses mendapat simpati penonton dan perhatian publik 
luas karena kemampuannya itu. Asép Sunandar dengan kreativitas yang ditelorkan, lambat laun membentuk dirinya sebagai dalang yang memiliki identitas dan ciri khas tersendiri. Olah kreativitas yang diaktualisasikan secara berbeda, dan mungkin hal itu luput atau tidak terpikirkan oleh dalangdalang yang lain.

Tidak heran, order jadwal panggungan dalang muda yang pada waktu itu berusia 29 tahun sangat padat. Untuk bertemu dengan sang dalang bisa dikatakan sangat sulit untuk dilakukan. Asép Sunandar tidak menyisakan satu hari pun jadwal panggungan yang kosong. Hal ini ditulis oleh Kompas sebagai berikut:

Selama dua bulan terakhir ini, tidak satu malam pun yang dilewatkan kosong dalam jadwal acaranya. Pagi atau siang hari dijadikan waktu istirahat, mempersiapkan diri untuk malam selanjutnya. "Malam ini di Cikole Lembang," kata Mustafa, kakak iparnya. "Besok di Subang dan lusa di Soreang". Dalam setahun, hari-hari kosongnya yang mulus hanya pada bulan Puasa dan Safar. Bulan Puasa pastinya dianggap tidak pantas untuk kenduri karena umat Islam menjalankan ibadah Puasa, sedangkan bulan Safar dianggap bulan pantangan oleh masyarakat Jawa Barat. "Bulan kawin Anjing", kata Asep Sunandar. ${ }^{3}$

\section{Asep Sunandar dan Proses Kreatif di awal Ketenarannya}

Asép Sunandar Sunarya mulai 'nguntit' ayahnya, dalang Abah Sunarya, sejak berumur 18 tahun. Ia belajar dengan cara memperhatikan ayahnya memainkan wayang, menjalin cerita yang memikat penonton, dan juga mencermati serta memahami konvensi yang berlaku dalam pertunjukan wayang golék Sunda. Pelajaran yang serupa ini pernah diterima ayahnya, Abéng Sunarya, (yang biasa dipanggil Abah Sunarya) dari kakeknya, yakni Dalang Juhari. ${ }^{4}$ Di samping itu, Asép Sunandar yang mulai merintis karier sebagai dalang pada tahun 1973, selalu dipenuhi keingintahuan yang besar dan semangat untuk memperbaiki kompetensinya, ia pun mengikuti Kursus Pedalangan mengenai Teori Pementasan Wayang Golék selama enam bulan di RRI Bandung.

Asép Sunandar Sunarya sebagai dalang muda yang berbakat, kreatif dengan daya virtousitas tinggi, kerap didera polemik terhadap dirinya, terutama kritikan terhadap sajian penampilan wayang golék yang dibawakannya. Ada yang menilai dirinya sebagai dalang yang melanggar pakem, muatan lakon lebih condong pada bobodoran bukan syiar Islam, atau karena keberanian memodifikasi bentuk wayang hingga kepalanya bisa terbelah, nga- 
roko, muntah mie, calangap dan lain sebagainya.

Segala bentuk kritikan yang mewarnai perjalanan karier Asép Sunandar, tidak dipandang sebagai 'masalah yang besar', akan tetapi dianggap sebagai tantangan yang mesti dijawab melalui karya nyata, bukan sekedar wacana. Kritikan tersebut juga membawa ke arah kematangan diri untuk lebih dewasa, wisdom, bijak menyikapi permasalahan, dan tidak arogan. Bahkan kritikan menjadi motivasi untuk konsisten dengan gayanya yang khas, fokus, mengasah talenta, kreatif, dan memperlihatkan kualitas kemampuannya, serta memberikan kontribusi berarti bagi dunia pedalangan.

Menyikapi hal di atas, dalang Abah Sunarya, ayahnya Asép Sunandar mengemukakan hal-hal yang dipandang tabu untuk dilanggar pada sajian wayang golék seperti lakon yang kini tidak lagi kental dengan muatan da'wah seperti pada jaman para wali bukan menjadi masalah besar, karena jaman sudah berubah. Di samping itu, memang mayoritas penduduk Jawa Barat sudah banyak memeluk Islam. Konteks tersebut yang harus disikapi dengan cerdas oleh para dalang, ngindung ka waktu mibapa ka jaman, Artinya, wayang golék mesti menyikapi jaman yang dilaluinya dengan tampil dinamis beradaptasi dengan dinamika sosial budaya masyarakat pendukungnya. Banyak kesenian Jawa Barat yang tidak mampu beradaptasi dengan dinamika sosial budaya masyarakatnya, kini meratapi nasib karena tidak mendapatkan kesempatan untuk tampil di ruang publik yang luas, bahkan sedikit demi sedikit ditinggalkan oleh masyarakat yang dulunya menjadi pendukung utama dari kesenian tersebut, contohnya seni pantun ${ }^{5}$ yang kini bisa dikatakan mendekati kepunahan.

Dewasa ini yang dibutuhkan masyarakat adalah hiburan pelepas lelah setelah seharian beraktivitas mencari nafkah bagi keluarga, salah satunya diakomodir melalui pertunjukan wayang golék. Tidak menutup kemungkinan tema yang dibawakan terdiri atas muatan seperti guyonan, politik, da'wah, pendidikan, ekonomi, dan sosial kemasyarakatan, serta program pemerintah pada masa kemerdekaan. Menurut Abah Sunarya: “yang penting, dalang harus hapal ceritanya serta menguasai falsafah wayang. Ia pun mesti menguasai silsilah wayang, kalau tidak, bisa terjadi Gatotkaca jadi satria Astina atau Astrajingga anaknya Pandhita Dorna. Kalau begitu bisa gawat dunia pewayangan kita" ${ }^{6}$

Di samping konvensi yang berkaitan dengan garap wayang golék yang mesti dikuasai setiap dalang, ada aspek lainnya yang juga penting untuk 
dikuasai dalang. Dalang hidup dalam lingkungan sosial budaya Sunda yang melingkupinya, jelas mereka terikat sistem nilai dan pranata sosial yang berlaku dalam masyarakat tersebut. Oleh karenanya, dalang yang masagi dituntut untuk paham kebudayaan yang melingkupi kehidupan seni yang ditekuninya. Mereka dalam menyajikan pertunjukan wayang golék tidak dapat mengabaikan aspek-aspek sosial dan budaya dalam kehidupan masyarakat Sunda yang senantiasa mengalami perkembangan. ${ }^{7}$

Penjelasan di atas merupakan kesimpulan sementara bahwa perubahan adalah hal yang wajar dalam setiap sajian kesenian tradisi yang hidup dalam locus kebudayaan, termasuk pertunjukan wayang golék. Berbicara mengenai tradisi yang senantiasa berubah, berikut adalah kutipan mengenai tradisi dalam buku Seni dan Pendidikan Seni: Sebuah bunga Rampai (2003), sebagai berikut:

Sebuah tradisi tidak pernah berhenti. Ia senantiasa berkembang bersama dengan situasi dan konteks sosial yang melingkupinya. Tidak pernah ada suatu tradisi yang tidak berubah. Jika ada tradisi yang tidak berubah, berarti tradisi tersebut telah selesai, bahkan mati... dalam konteks ini tradisi harus dilihat sebagai 'kata kerja' bukannya 'kata benda'. Bukan etalase, melainkan proses kinerja di balik 'etalase' tersebut (Masunah. 2003:133).

Tradisi sendiri tidak bisa lepas dari proses kreativitas, karena kedua aspek tersebut merupakan 'dua sisi mata uang logam' yang saling berkaitan dan tidak bisa dipisahkan satu sama lain. Konsep tradisi dan hubungannya dengan kreativitas dijelaskan Saini KM sebagai berikut:

Kreativitas adalah kemampuan mengidentifikasi masalah secara tepat dan memberikan jawaban yang tepat pula terhadapnya. Hasil kreativitas, baik yang bersifat ragawi maupun jiwani, yang terkumpul dalam masa yang lama dan tersusun dalam tatanan (sistem) tertentu, itulah yang bernama tradisi (Saini, 1999:10).

Inovasi dan perkembangan garap yang dilakukan Asép Sunandar dengan proses kreatif terhadap seni tradisi yang digelutinya, mendudukan dirinya sebagai seniman agent of change (agen perubahan), dan memang wajar terjadi pada setiap jaman, di mana selalu bermunculan senimanseniman yang berperan sebagai agen perubahan terhadap jenis kesenian yang mereka geluti. ${ }^{8}$ Seniman yang mampu bertindak sebagai agent of change, pada umumnya melahirkan karya yang fenomenal, ataupun memberi tafsir baru terhadap genre kesenian yang telah ada dan berpengaruh kuat terhadap kehidupan 
berkesenian pada jamannya (Waridi, 2003:356).

Di tengah-tengah kritikan mengenai proses kreatif Asép Sunandar Sunarya, dalam menampilkan inovasi garap pada penyajian garap wayang golék yang diusungnya, mendapatkan sambutan positif dari tokoh budayawan melalui Surat Kabar Kompas pada tahun 1984 sebagai berikut:

Sikap dan cara dalang Asép memperlakukan wayang untuk mengingat dan memikat publik penontonnya, agaknya belum tentu diterima oleh semua pihak. Tetapi tokoh budayawan Enoch Atmadibrata nampaknya berpikiran lebih maju. Dia menilai dalang Asép sudah melangkah ke arah yang lebih jauh. "bahkan seharusnya lebih dari itu", katanya. Nampaknya Enoch menilai positif. Malah ia me-

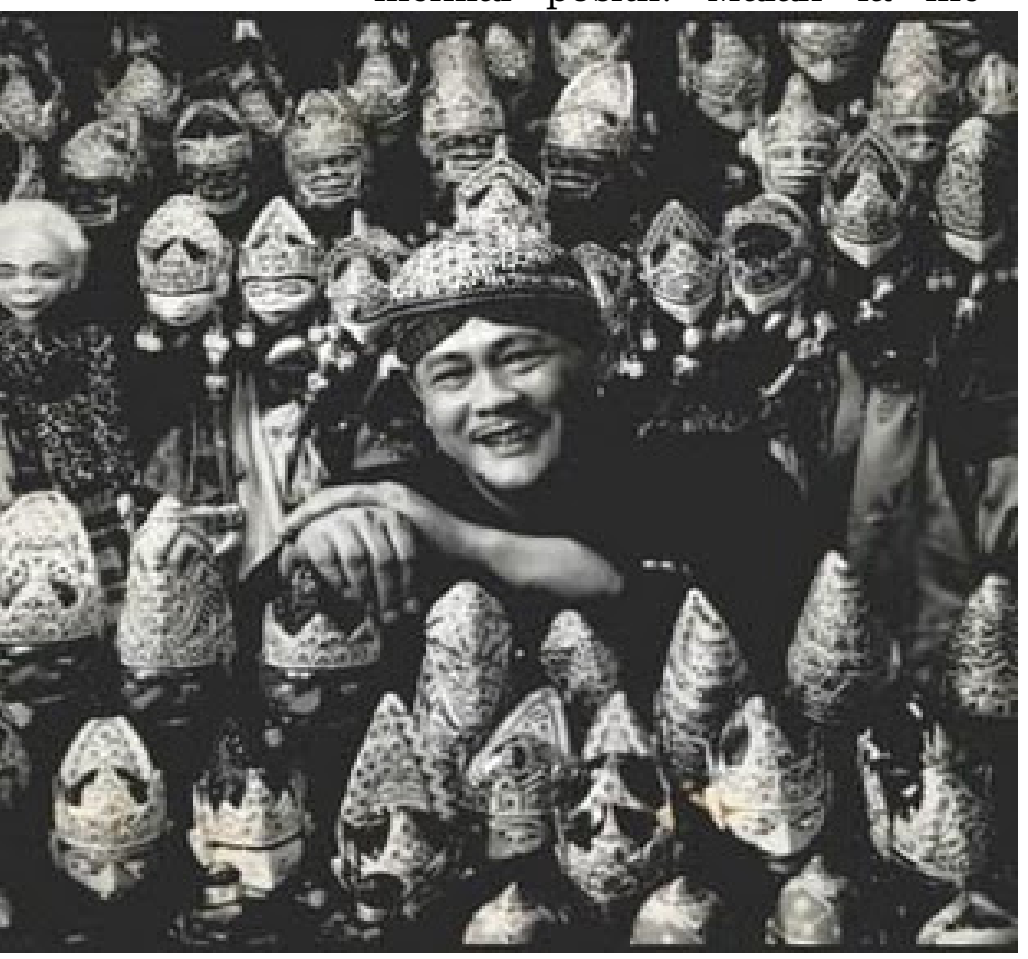

Asep Sunandar Sunarya bersama boneka wayang golék yang menjadi medium kreativitasnya nganjurkan dalang agar banyak membaca untuk bisa mengetahui perkembangan di sekitarnya. "Wayang golék, kalau mau berkembang harus seperti itu. Jangan kepalang dalam pementasannya. Misalnya pakai dekor dan tata lampu', katanya ... di masa datang, demikian selanjutnya, wayang golék modern mungkin tidak hanya menyampaikan cerita lama. "Mungkin saja nantinya, Si Kabayan bisa dipentaskan, atau cerita perjalanan ke Planet Mars" kata Enoch (Kompas, 25 Nopember 1984: 7).

Pada akhirnya Asép Sunandar mendudukkan diri sebagai dalang senior yang menjadi trendsetter (kiblat) para dalang muda. Andrew Weintraub dalam bukunya berjudul Power Play:Wayang Golek Puppet Theater of West Java (2004) menyebutnya dengan istilah superstar dalang. Para dalang muda mengimitasi keterampilan yang dipraktikkan Asép Sunandar, dari cara penyajian murwa ${ }^{9}$, suluk ${ }^{10}$, kakawen ${ }^{11}$, sabet wayang, ${ }^{12}$ antawacana, ${ }^{13}$ bodoran $^{14}$ hingga garap gending dari grup Giri Harja III pimpinan dalang Asép Sunandar Sunarya. Bahkan warna suara dan dialek Astrajingga yang dibawakan Asép Sunandar menjadi trademark yang melekat di hati masyarakat Jawa Barat. Suara Astrajingga versi Asép Sunandar menjadi patokan bagi dalang-dalang muda untuk sepercis mungkin dapat menirunya, syarat yang mau tidak mau, suka atau tidak suka harus dipenuhi apabila keberadaan mereka ingin 
diterima masyarakat Jawa Barat yang familiar dengan Astrajingga dan panakawan yang dibawakan Asép Sunandar Sunarya.

Kepopulerannya mengimbas pada pemasukan yang diterima Asép Sunandar untuk satu kali panggungan. Biaya tanggapan di luar kota berkisar 60-100 juta rupiah, sedangkan di dalam kota Bandung sebesar 40-50 juta rupiah. Jumlah penghasilan kotor yang prestisius untuk penghasilan dalam satu malam.

Alasan pematokan harga panggungan yang tinggi, di samping memang sebanding dengan kualitas Asép Sunandar sebagai superstar dalang, juga merupakan kiat yang bersangkutan untuk menyaring banyaknya jumlah order panggungan. Dapat dibayangkan apabila biaya panggungan terjangkau atau murah meriah, rombongan Asép Sunandar kebanjiran order dari masyarakat yang mengadakan kenduri. Apabila demikian, maka hal ini sama saja dengan memonopoli pa-sar. Maka. dengan pematokan harga yang tinggi, masyarakat yang tidak sanggup untuk nanggap Asép Sunan-dar bisa memilih alternatif dalang-dalang lain yang ada di Jawa Barat. Hal ini merupakan kiat Asép Sunandar
Sunarya untuk memberikan lahan garapan bagi para dalang lainnya dan juga menepis kecurigaan negatif yang menengarai bahwa ia memonopoli pasar wayang golék di Jawa Barat.

\section{Penonton yang Meminati Pertunju- kan Wayang Golék Asép Sunandar}

Di daerah Jawa Barat, perayaan perkawinan diisi dengan pertunjukan kesenian yang berlangsung semalam suntuk. Misalnya orkes dangdut atau jaipongan. Tetapi kedua kesenian tersebut acapkali menundang onar akibat perkelahian anak-anak muda yang berjoget. Wayang golék biasanya merupakan pilihan banyak orang, terutama kalangan orang tua. Alasannya bukan hanya karena keamanannya, tetapi untuk kesenian tradisional yang dipergelarkan semalam suntuk itu dinilai meriah. Penonton tidak hanya dapat menikmati nyanyian dari pesinden tetapi bisa mencermati jalannya cerita. ${ }^{15}$

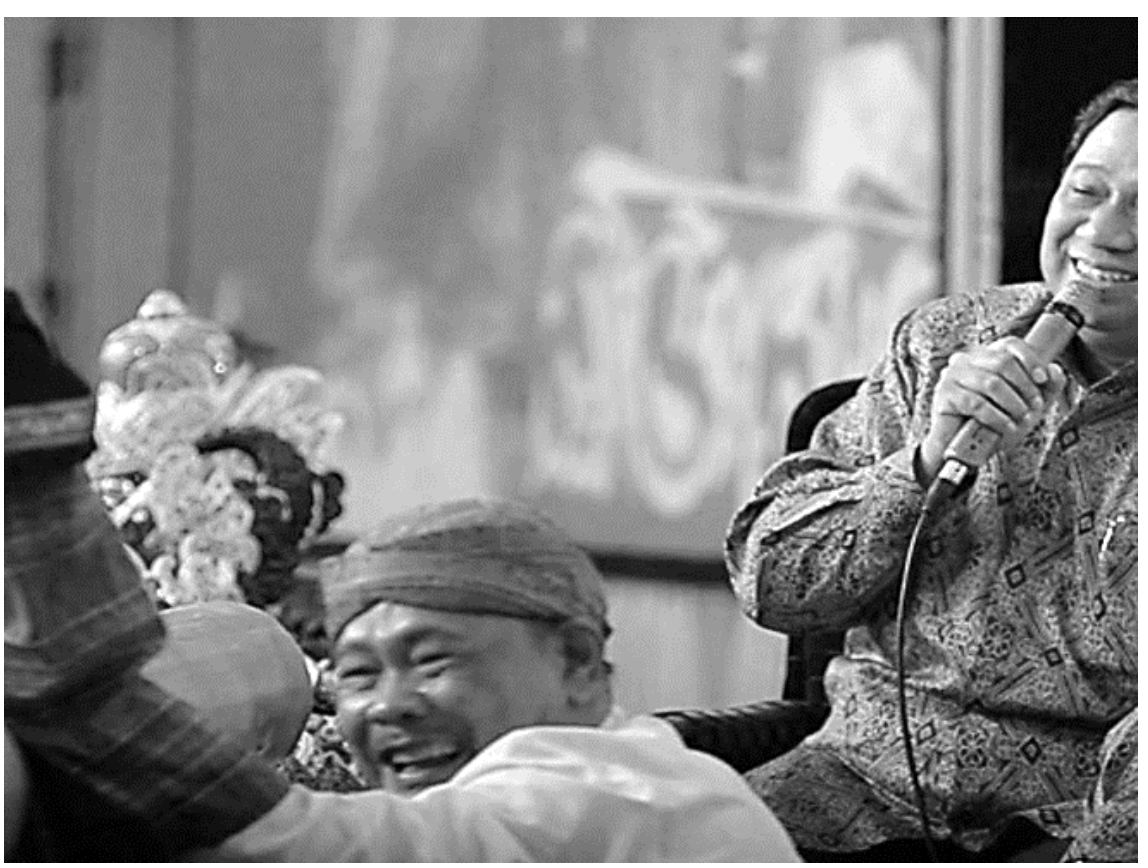

Asép Sunandar memainkan wayang golék sambil berdialog dengan Persiden RI ke-6, Susilo Bambang Yudhoyono 
Asép Sunandar dengan rombongan Giri Harja III yang ia pimpin, merupakan pilihan favorit yang kerap menye-marakkan acara hiburan wayang golék semalam sun-tuk. Para penonton yang menyaksikan bukan sekedar kalangan orang tua, tetapi di antaranya adalah anak-anak muda. Mereka berjejal berdesak-desakan menyak-sikan pertunjukan hingga bertahan sampai subuh. Di sekitar panggung dan sepanjang jalan menuju tempat pertunjukan, dipenuhi para pedagang yang menjajakan beraneka ragam dagangan, dari jenis makanan kuliner, pakaian, dan mainan anakanak. Para pedagang ini, berasal dari lokal setempat, dan ada pula yang berasal dari luar daerah (biasanya pedagang kelompok terakhir adalah pedagang tetap yang khusus dikoordinir untuk hadir di setiap lokasi panggungan Asép Sunandar di pelosok daerah di Jawa Barat). Mereka berkerjasama dengan 'orang dalam' dari rombongan wayang agar bisa mengetahui alamat dan jad-wal panggungan secara tepat. Keber-adaan Asép Sunandar dengan jadwal panggungan padat, ternyata memberikan lahan pendapatan bagi para pedagang untuk bisa memperoleh penghidupan bagi keluarga dan menjaga asap dapur tetap mengepul. Karang Taruna di tempat hajatan pun mendapatkan keuntungan dari pungutan uang parkir dari para penonton dan tamu undangan yang datang.

Fenomena keramaian penonton dan pedagang di lokasi pertunjukan Asép Sunandar Sunarya dicatat Andrew Weintraub, sebagai berikut:

The road leading in to the village was filled with vendors selling hats, shoes, toys, clothes, and many varieties of food. The smell of fried cassava, clove cigarettes, and grilled skewered meat hung heavily in the hot humid evening air. People of all ages had started gathering to see what was going on (2004:2).

Terjemahannya

Jalan yang menuju ke desa itu dipenuhi pedagang yang menjual topi, sepatu, mainan, pakaian, dan berbagai jenis makanan. Aroma goreng singkong, rokok kretek, dan daging panggang yang ditusuk (sate) membumbung tinggi di udara malam yang panas dan lembab. Orang dari segala usia mulai berkumpul untuk melihat apa yang terjadi.

Pada saat Asép Sunandar memainkan babak di mana para panakawan muncul, celetukan humor dan dialog para panakawan mengundang tawa penonton. Perut mereka seperti dikocok-kocok, tertawa terpingkal-pingkal dari awal hingga akhir. Bahkan ketika dialog para panakawan menyentil kondisi pemerintahan negara Astina yang carut-marut, secara tidak sadar penonton terbawa emosi, ikut 
merasakan apa yang dirasakan oleh para panakawan, karena ternyata kasusnya sama dengan yang dirasakan penonton. Mereka pun bertepuk tangan riuh ketika Astrajingga dan adikadiknya menyampaikan kekesalan dan kritik membangun aspirasi rakyat kecil untuk negara Astina. Di sinilah kejeniusan seorang dalang seperti Asép Sunandar. Ia pintar membaca peta kondisi dan situasi masyarakat Indonesia yang diluruhkan dalam lakon wayang. Bahkan lakon yang diambil dari cuplikan epos Mahabrata dan Ramayana yang berusia ribuan tahun, terasa up to date di jaman sekarang, ketika Asép Sunandar mengemasnya dalam sajian cerita (Nugraha 2015).

Kecerdikan dalang Asép Sunandar dalam mengemas lakon dengan sisipan kritikan pedas dan guyunan humor, memang telah terpupuk dari awal kemunculannya. Hal ini ditulis kompas (1984) sebagai berikut:

Dengan cerita Sanghyang Ajar Sakti, pertengahan April tahun lalu Asep tampil di hadapan penonton yang terdiri dari pejabat teras di Jawa Barat yang memenuhi lobby Grand Hotel Preanger Bandung, walaupun sindirannya seringkali membikin merah telinga, Asep mampu mengimbangi penampilannya dengan banyolan segar sehingga penonton tak henti-hentinya dikocok perutnya. Penonton tak beringsut sampai pagi. ${ }^{16}$
Sangat berbeda ketika menyaksikan wayang golék garapan Asep Sunandar dan dalang yang lain di sini saya tidak bermaksud membuat pendikotomian - terutama jumlah penonton yang hadir menyaksikan pertunjukan. Kalau yang manggung adalah dalang kondang Asép Sunandar Sunarya, dipastikan penonton tumpah ruah memadati lokasi pertunjukan, bahkan sepanjang jalan menuju lokasi, ramai dengan pedagang yang juga dipenuhi pembeli, dengan jarak tempuh bisa mencapai 1/2 (setengah) km.17 Hal ini bertolak belakang ketika dalang yang tampil tidak populer, terasa begitu sepi penonton. Semakin larut malam, jumlah penonton semakin berkurang, yang bertahan adalah orang tua yang memang fanatik terhadap wayang golék. Begitu subuh jumlah penonton sangat coréngcang, jumlah yang minim sekali.

Kondisi penonton semacam ini menandakan bahwa memang ada pembagian tipologi penonton yang menyaksikan pertunjukan wayang golék. Pertama, penonton apresiatif yang betulbetul menikmati tontonan dan larut secara emosional dengan penampil (dalang) bersangkutan (penggemar dan yang diidolakan); kedua, penonton yang mengapresiasi pertunjukan wayang golék secara rasional tetapi tidak larut secara emosional dengan penam- 
pilnya (penonton dengan performer); dan ketiga, penonton yang hadir tanpa pretensi dan hadir karena ajakan teman-teman atau melihat keramaian penonton yang hadir (audiens versus atmosfir).

Ketiga jenis tipologi penonton ini dalam pertunjukan wayang golék Asép Sunandar dan dalang-dalang yang lain, dipastikan hadir. Namun perbedaannya, nama besar Asép Sunandar Sunarya sebagai 'dalang kondang', banyak menghadirkan penonton jenis tipologi pertama, yakni penonton yang benar-benar mengidolakan tokoh karismatik dalang tersebut. Tak heran audience yang menonton pertunjukan wayang golék dalang Asép Sunandar di suatu daerah bukan hanya masyarakat sekitar atau tamu undangan saja, melainkan juga penonton yang berbeda kampung dan kecamatan, yang sengaja ingin menonton pertunjukan dalang kondang tersebut. Sudah bukan rahasia lagi, apabila Asép Sunandar akan manggung di suatu daerah, kabar beritanya sudah tersebar di seantero daerah tersebut, yang memang fanatisme terhadap dalang Asép Sunandar 'sangat kuat' sekali.

Selain ikatan emosional
terhadap dalang Asép Sunandar Sunarya, ada banyak alasan, mengapa penonton banyak ditemui pada pertunjukan wayang golék Giri Harja III.
Selain pertunjukan yang merakyat dan gratis, penonton memiliki ruang luas untuk mengapresiasi pertunjukan secara lebih bebas dengan lakon yang dijamin menarik untuk dicermati (bisa sambil merokok, makan, cari jodoh, belanja dll); atau juga memburu kesenangan semata (hiburan). Mereka secara langsung mendapatkan kesempatan langsung menikmati alunan gending wayang dengan sinden yang hanya dikenal melalui kaset komersial atau televisi. Dengan menonton wayang golék, mereka mendapatkan suasana pertunjukan yang memberi ruang-ruang pelepasan emotif, tertawa karena ulah wayang Panakawan, dan larut dalam jalannya cerita. Weintraub menuliskan alasan penonton yang ingin menonton pertunjukan Asep Sunandar sebagai berikut.

Most of the spectators had come to hear Asep Sunandar's bawdy Sundanese jokes. Other came to watch him bring the puppets to life in tightly choreographed battle scenes. And still others were there to watch and to listen to the female singers and the powerful drumming of jaipongan, a popular form of Sundanese dance and music (Andrew Weintraub, 2004: 4).

Banyaknya peminat atas kepiawaian Asép Sunandar Sunarya dalam mengolah pertunjukan wayang golék, tidak hanya di kalangan masyarakat Sunda saja, masyarakat mancanagara 
pun sangat antusias terhadap dalang kondang ini. Beberapa kali Asép Sunandar beserta rombongannya diundang pentas di luar negeri. ${ }^{18}$ Bahkan pada tahun 1993 Asép Sunandar menjadi Honorable Lecturer di Instritut International de La Marionnette, Prancis, dan mendapatkan gelar kehormatan profesor. Di samping itu, karena dipandang memiliki nilai marketable tinggi, selain rekaman kaset komersial, Asép Sunandar juga mengasuh pertunjukan komedi Asép Show di Televisi Pendidikan Indonesia (TPI), wayang Astranjingga dan pelawak nasional berkolaborasi menghibur masyarakat Indonesia setiap bulan Ramadhan, dari tahun 1994-2004. Tahun 2005, Asép Sunandar dan grup Giri Harja III dikontrak Televisi Pendidikan Indonesia, 36 episode, untuk tayangan pertunjukan wayang golék di layar kaca setiap malam minggu. Produsen obat Aladina juga mengontrak Asép Sunandar sebagai bintang iklan obat tersebut. Asép Sunandar memang fenomenal untuk ukuran seniman tradisi. Ia mampu melebarkan sayapnya dari tingkat regional, nasional, hingga internasional.

\section{Kesimpulan}

Melalui tangan dingin Asép Sunandar, wayang golek menjadi seni pertunjukan yang menarik minat masyarakat Jawa Barat, dari berbagai kalangan usia. Bahkan wayang golék diangkat ke level paling atas. Tidak hanya pentas di pelosok daerah saja, tetapi mampu mempresentasikan diri di ruang publik yang lebih luas pada skala nasional dan internasional.

Wayang golék masih menjadi kesenian yang paling populer di Jawa Barat, walaupun pada dulunya difungsikan sebagai media da'wah para wali untuk merekrut para penonton memeluk Islam, kini seiring dengan perkembangan jaman, wayang golék menjadi multi fungsi, karena mayoritas masyarakat Jawa Barat telah menganut agama Islam, wayang golék tidak sekedar sebagai media da'wah, juga hiburan, penerang program pemerintah, dan lebih jauhnya lagi mampu mencitrakan (identitas) suatu suku bangsa dan juga bangsa di mata dunia. Otomatis penikmat wayang golék kini tidak sekedar orang Sunda, Jawa Barat saja, tetapi Indonesia, dan dunia internasional.

\section{Catatan Akhir}

${ }^{1}$ Lihat Kompas, 25 November 1984. Asep Sunandar Sunarya si "Dalang Sadis" Minggu, 25 Nopember 1984. halaman 7. kolom 1.

Wayang pakem adalah wayang yang menjadi konvensi dan masih dianggap tabu untuk mendapatkan sentuhan kreativitas yang radikal. Wayang pakem ini seperti tokoh-tokoh dari golongan wayang satria dan dewa.

${ }^{3}$ Lihat Kompas, Asep Sunandar Sunarya si "Dalang Sadis" Minggu, 25 Nopember 1984. halaman7. Kolomon 2 \& 3. 
${ }^{4}$ Wawancara dengan Dinar Mustika (36 tahun), anak kandung Asep Sunandar Sunarya, tanggal 6 Mei 2016.

${ }^{5}$ Seni pantun telah disinggung dalam Sanghyang Siksa Kandang Karesian, naskah kuna masyarakat Sunda yang dibuat pada masa pemerintahan Sri Baduga Maharaja (1482-1521) atau $1518 \mathrm{M}$, adalah pertunjukan teater tutur, bercerita sambil bernyanyi dengan iringan kacapi. (Nugraha 2007:132)

${ }^{6}$ Lihat Kompas, Wayang Golek Berubah Istri bisa Serong. Minggu, 25 Nopember 1984. hal.7. Kolom 1.

${ }^{7}$ Wawancara dengan Tutun Hata Saputra, tokoh pedalangan Jawa Barat. Tanggal 5Mei 2016.

8 Seniman Jawa Barat yang berperan sebagai agent of Change, di antaranya: Dalem Pancaniti, R.T.A Soenarya, R. Sambas Wirakusumah, R. Tjetje Soemantri, Gugum Gumbira, Koko Koswara, Ismet Ruhimat, dan Asep Sunandar Sunarya (Komala 2015).

${ }^{9}$ Murwa adalah kata-kata pembukaan dalang wayang setelah kakawen, biasanya menggunakan bahasa kawi, tapi ada juga yang menggunakan bahasa Sunda, diucapkan sambil diiringi gamelan (Ajip Rosidi, 2000:425).

${ }_{10}$ Suluk adalah nyanyian dalang pada setiap awal adegan setelah gamelan berhenti dan akan memulai percakapan; atau ditengah-tengah adegan setelah ada kejadian atau percakapan yang menimbulkan reaksi keras pada salah seorang tokoh (Ajip Rosidi, 2000:614).

${ }_{11}$ Kakawen adalah vokal dalang yang dibawakan untuk menggambarkan keadaan keadaan suatu adegan yang akan atau tengah diceritakan (Asep Nugraha, 2008:72).

12 Sabet wayang adalah keterampilan dalang dalam memainkan wayang, ketika adegan tari atau perkelahian.

13 Antawacana adalah kemampuan pengaturan timbre/warna suara, diksi, fonasi, intonasi, dan surupan (nada dasar) sehingga dialog yang terjalin lebih hidup serta harmonisasi suara vokal dalang dengan laras gamelan menjadi selaras.

14 Bodoran adalah kepiawain dalang menyusun lawakan yang mengena di hati apresiator.

15 Lihat Kompas, 25 November 1984. Asep Sunandar Sunarya si "Dalang Sadis" Minggu, 25 Nopember 1984. halaman 7. Kolom 4.
16 Lihat Kompas, Asep Sunandar Sunarya si "Dalang Sadis" Minggu, 25 Nopember 1984. halaman 7. Kolom 4.

17 Penulis menyaksikan sendiri ketika Asep Sunandar manggung karena penulis adalah juru sinden dari rombongan Giri Harja III.

${ }^{18}$ Asep Sunandar dan rombongan Giri Harja III mengadakan tour ke Amerika Serikat (1989), menghadiri Puppet Festivity di Prancis (1992), tour wayang golek keliling Eropa (1994), tour wayang golek di 12 kota di Inggris bekerjasama dengan Asian Music Circuit (2001), pertunjukan wayang golek dengan America Music Circuit (AMC) dan selama 40 hari workshop wayang golek di Inggris (2006). (lihat. http:// en. wikipedia. org/wiki/Asep_Sunandar_Sunarya)

\section{Kepustakaan}

Kompas. 1984. "Asep Sunandar Sunarya si Dalang Sadis.”Minggu, 25 Nopember.

1984. "Wayang Golek Berubah Istri bisa Serong."Minggu, 25 Nopember.

Komala, Icuh. 2015. "Kompetensi Enoch Atmadibrata Pada Kesenian Jawa Barat." Jurnal Ilmiah Seni \& Budaya Pantun Vol. I No. 1. Bandung: Pascasarjana ISBI, 16-33.

Nugraha, Asep. 2007. "Pemain Kacapi Indung Seni Tembang Sunda Cianjuran: Kajian Peraihan Derajat Kompetensi." Laporan Penelitian Beasiswa Unggulan. Bandung: STSI Bandung.

- 2015. "Angklung Tradisional Sunda: Intangible, Cultural Heritage of Humanity, Penerapannya Dan Pengkontribusiannya Terhadap Kelahiran Angklung Indonesia." Awi Laras Prodi Angklung Dan Musik Bambu. Bandung: ISBI 2 (1). 
Kosim, Saini. 1999. "Pelik-Pelik Kebudayaan Sunda". dalam Jurnal Budaya Dangiang: Menggali Kuburan Orang Sunda.edisi I/MeiJuli . Jakarta: PT Dunia Pustaka Jaya.

Masunah, Juju.,\& TatiNarawati. 2003.Seni dan Pendidikan Seni: Sebuah Bunga Rampai. Bandung: P4STUPI.

Nugraha, Asep. 2008. "Penelusuran dan Perkembangan Kacapi Sunda." Dalam jurnal Paraguna Vol 2 No 1. Bandung: Prodi Karawitan.

Rosidi, Ajip. 2000.Ensiklopedi Sunda: Alam, Manusia, dan Budaya. Jakarta: Pustaka Jaya.

Waridi. 2003. Seni dalam Berbagai Wacana Mengenang 20 tahun Kepergian Gendhon Humardani. Surakarta:
Program Pendidikan Pascasarjana Sekolah Tinggi Seni Indonesia.

Weintraub, Andrew. 2004.Power Play: Wayang Golek Puppet Theater of West Java. Ohio University Research in International Studies.

\section{Nara Sumber}

Dinar Mustika (36 tahun), seniman dan anak kandung dalang Asep Sunandar Sunarya, Jelokong, Ciparay, Kabupaten Bandung

Tutun Hatta Saputra (58 tahun), Seniman dan TFA Jurusan Karawitan Sekolah Tinggi Seni Indonesia Bandung, Jelekong, Ciparay, Kabupaten Bandung 